\title{
Thabes
}

\section{Miss Scarlet, dans la bibliothèque, avec une mitrailleuse}

\author{
LORI SAINT-MARTIN \\ Écrivaine canadienne
}

t voilà que nous avons trouvé refuge ici, dans cette demeure ancestrale, fuyant la Mort rouge qui règne au-dehors, ce manoir avec ses salles bleues ou vertes ou violettes, orangées, blanches, sa bibliothèque aux murs tapissés de la sagesse des siècles, sa longue galerie de miroirs. Moi qui suis seule au monde, mon frère disparu dans la guerre, mes parents morts de chagrin, j'ai bien de la chance d'être ici, à l'abri. De la chance d'avoir pu m'installer chez mon oncle et tuteur, M. Green, veuf de frâiche date, de couler des jours faciles en sa compagnie et celle des quatre proches qui venaient tout le temps au château de mes parents, vider leur cellier et remplir l'air de la fumée de leurs cigares — même les femmes fument le cigareet de leurs bavardages. Mon oncle a liquidé le château et toutes nos autres propriétés, l'argent repose dans une banque lointaine « en attendant ton mariage », me dit-il. Entre-temps, il me fait la bonté de m'accueillir sous son toit. Et nous voici tous les six, oisifs, du matin au soir. L'université fermée, mes études suspendues, je lis les classiques dans la bibliothèque. Toutes les pièces nous sont ouvertes, sauf la petite bibliothèque de feu ma tante où, enfant et jeune fille, j'ai passé tant d'heures heureuses avec elle à me faire raconter des histoires. Mon oncle nous en interdit l'accès, je n'ose lui demander

\section{Pour citer ce texte}

Saint-Martin, L. (2021). Miss Scarlet, dans la bibliothèque, avec une mitrailleuse. Hybrida, 2 227-231. https://dx.doi.org/10.7203/HYBRIDA.2.21221 
pourquoi. Nous sommes entre nous, du matin au soir, réfugiés, prisonniers de la peste. Entre ces murs, la sécurité, dehors, la Peste rouge.

Mais bien sûr nous ne sommes pas seuls, nous dont le sang bleu nous vaut obéissance et considération : un nombreux personnel est à notre service, belles jeunes femmes à la peau sombre sanglées dans de petites robes noires, juchées sur de hauts talons. Elles vont et viennent, les yeux baissés, ne voient pas mes timides sourires. Elles ont mon âge, vingt ans à peine, j'aimerais parler avec elles, savoir quelles images cachent leurs paupières, quelles histoires elles taisent. Mon oncle les appelle toutes « Maria ». Avec sa haute taille et sa barbe si noire qu'elle en paraît bleue, en smoking comme le colonel et le professeur, mon oncle a fière allure en causant avec les dames, tirées à quatre épingles elles aussi. Dans l'armoire de ma chambre, en arrivant, j'ai trouvé une douzaine de robes du soir, toutes différentes mais toutes écarlates, exactement à ma taille. J'ignorais que mon tuteur m'avait étudiée de si près. « Rien de trop beau pour ma petite nièce chérie », me dit-il. Escarpins et fines sandales à ma pointure, jupes froufroutantes et fourreaux moulants, lourds bijoux qui font ployer mon cou, entravent mes gestes. Mes vêtements d'avant ont disparu, personne ne semble savoir où.

Le soir, mon tuteur me verse lui-même le vin dans une coupe cramoisie qu'il a choisie pour moi. Je n'ai jamais le temps de vider la coupe avant de mécrouler dans le salon ou dans la salle de billard. Le matin, je me réveille dans mon lit, déshabillée, ma robe en corolle sur le plancher. À part un léger vertige, je me sens bien. Les jours passent et il me semble qu'il y a moins de bonnes qu'avant, je n'arrive pas à les compter, la tête me tourne. Quand j'ai demandé à l'une d'elles comment elle s'appelait, si elle comprenait ce qui se passait ici, elle a secoué la tête sans un mot.

Le temps passe, la peste rôde, l'ennui monte. On boit, on fume, on bavarde sans entrain. Un soir, très tard, mon oncle dit :

- Scarlet, ma chérie, nous allons jouer à un jeu. Viens près de moi.

Je m'avance vers cet homme à la barbe si bleue, au sourire si bon. Les autres se redressent, attentifs soudain. La pièce crépite.

Sans se départir de son bon sourire, sans me quitter des yeux, mon oncle saisit un couteau qui traîne sur la table, à côté d'un panier de fruits, et me fait une longue estafilade sur le bras.

-Nous, on sera les chasseurs et toi tu te sauveras de nous, c'est un divertissement merveilleux, tu vas voir. Allez, c'est parti, cours!

Je regarde mon oncle, c'est un inconnu. Je me tourne vers les autres, personne 
n'est surpris, personne ne tend la main vers moi. Ma tête se vide, mon bras brûle. Comment des femmes peuvent-elles être mêlées à cette histoire?

- C'est parti, j'ai dit!

Rez-de-chaussée, portes verrouillées, fenêtres incassables, dehors sur la grande pelouse je devine des silhouettes sombres, des pestiférés sans doute, ou des complices de mes poursuivants. Pas moyen d'échapper à cette maison. Ses recoins, ses culs-de-sac, ses portes dérobées dont je dois me rappeler l'usage même si je ne suis pas chez moi ici, contrainte que je le suis à habiter le royaume d'un autre.

Une maison, c'est grand. Une maison, c'est petit quand on cherche une cachette sûre. Une maison, c'est une boîte, un cercueil.

La salle de billard, la salle de bal, le petit salon. La bibliothèque. Les rangées de livres au dos doré où la fin de l'histoire est déjà écrite. Emma, Anna, Ophélie et tant d'autres. Derrière moi, des voix chuchotées, mêlées à de petits rires.

-On ne va pas te faire de mal, poupée, viens, on veut juste te faire du bien...

Dans la galerie des miroirs, ma silhouette rouge et mon visage effrayé, démultipliés. Au-delà des glaces, je vois une caméra.

Je presse le pas, les pieds nus parce que je me suis défaite de mes chaussures à talons aiguille, et je vois qu'il a des caméras partout, comment se fait-il que je ne l'aie jamais remarqué, ils filment le spectacle pour le faire durer, me faire durer même après, pour voir si je supplie, si je crie, si je pleure ou me débats.

Impossible de courir si vite que la caméra échouera à capter notre passage. Je me vois jouer dans un film en noir et blanc, ma robe la seule tache de couleur. Je contemple cette demeure de très haut, comme une maison de poupées sans toit, je plane dans le ciel étoilé et je vois courir, toute petite et toute désespérée, une jeune femme en rouge, une jeune femme en rage, une bientôt morte, une presque morte, et derrière elle, la meute de ses poursuivants, menés par son tuteur, son tueur, ses poursuivants qui avancent sans se précipiter, car nous savons tous qu'une maison n'a pas un nombre infini de pièces : la petite arrivera bientôt au bout et alors nous la tiendrons, une maison c'est un livre dont la fin est déjà écrite, un livre c'est un labyrinthe et la jeune fille court sans le savoir vers le Minotaure.

Mais bien sûr, elle le sait, et son désespoir avive notre plaisir. Elle sait, tout à coup, ce qui est arrivé aux bonnes, par ces nuits où elle dormait d'un sommeil de plomb après avoir vidé la coupe cramoisie. 
Je l'ai déjà vu, ce film, je l'ai déjà lu, ce livre, le cadavre à peine vêtu d'une jeune femme dans un lit, dans une baignoire, un boisé ou le coffre d'une voiture. Le détective désabusé qui secoue la tête, la meute des reporters et le crépitement des flashes, le corps mutilé amoureusement détaillé, le visage jeune et étrangement paisible, le fondu au noir.

Est-ce moi la protagoniste aux abois ou est-ce une autre qui veut s'évader, séclipser, échapper à leurs armes blanches à leurs armes de poing à leurs poings? Pourtant, que de fois on a mangé ensemble, joué au billard et aux cartes ensemble, bâillé et ri de concert dans ces pièces fermées.

Du coin de l'œil, je vois surgir une forme. Je ne les croyais pas si près et un cri m'échappe.

- Chut, dit une voix (c'est l'une des bonnes, maintenant en pantalon et veste de cuir), écoute-moi bien.

D’un seul geste assuré, elle ouvre le mur. Fait coulisser doucement un panneau par où je m’engouffre aussitôt, chuchote :

- Rends-toi à la bibliothèque de ta tante, tu trouveras des armes dans le placard. Elle est morte trop vite, on n'a pas pu la sauver.

Le joli petit cabinet de lecture, ma tante qui me racontait des histoires neuves, moffrait des livres au dénouement différent, me parlait de Virginia et de sa sœur Vanessa, de Charlotte et d'Emily, d'Anne et d'Anais, de Sylvia, de Jane, de Gabrielle et de Rachilde et de Renée, ma tante curieuse, elle dont nous n'avons jamais vu le cadavre, seulement la pierre tombale. Morte de fièvre, nous avait-on dit, bouche cousue, pièce condamnée. Déjà de son vivant, si la porte nétait jamais verrouillée, le placard était sous clé. «J'ai mes petits secrets, disait-elle, grave soudain, elle si rieuse. Un jour, on l'ouvrira, toi et moi, et on partira en voyage. »

Je les entends, derrière, un peu plus près encore. Mais j’y suis presque, j’y suis.

La porte toujours fermée est grande ouverte. Le placard aussi, une main amie a tout déverrouillé.

Pour la première fois, je vois le contenu de ce placard secret. Trois objets bien alignés.

Une mitrailleuse, une épée, une plume.

Miss Scarlet, dans la bibliothèque. Avec une mitrailleuse.

Je les entends rire, je les entends avancer. D'un instant à l'autre, la porte s'ouvrira. 
Je ne veux pas les abattre, je ne veux pas les poignarder. Je refuse de basculer dans leur camp, même si ce serait peut-être, je le vois soudain, pour venger ma tante.

Mais je veux persister, je veux signer. Ma tante m'a fait cadeau d'une plume toute neuve, la plus belle qu'il m'ait été donné de voir, et je sens germer en moi une histoire inédite, une histoire qui n'a pas ma mort au bout. Je nous veux, celle qui m'a ouvert les portes, les autres jeunes femmes de cette maison et moi, ensemble, en train de rire et de danser devant un feu de joie.

Tout à coup, je vois : la fenêtre n'est plus qu'un cadre béant, sans vitre. Je me précipite, me penche dans le vide, sens sur ma peau l'air frais et doux de la nuit.

Derrière moi, chaleur, crépitements, lueurs rouges. Les cris ont un autre ton, soudain.

- Venez, crie mon oncle, oubliez-la, il faut sortir!

Je me penche dans le cadre qui a déjà été une fenêtre et je les vois sur la pelouse, droites comme des statues, leur torche brandie bien haut dans la main droite, à contempler leur œuvre. Les bonnes qui nont pas de nom, les bonnes à tout faire, les bonnes à qui on croit pouvoir tout faire, lèvent les yeux vers moi, portrait d'une jeune femme à la fenêtre d'une demeure en feu. En bordure du groupe, est-ce possible, je crois deviner le visage d'une femme plus âgée.

- Je vous croyais mortes.

- Mais non, on est immortelles. Viens, on te dira nos vrais noms, tu nous diras le tien.

Elles rient, elles me tendent les bras. La peste règne partout, mais nous trouverons bien un endroit où atterrir.

Je saute. 